\title{
ANALISIS PERBANDINGAN KELAYAKAN EKONOMIS DARI BELT CONVEYOR DAN DUMP TRUCK UNTUK PENGANGKUTAN GIPSUM CURAH (Studi Kasus: Pabrik Pupuk di Kota Gresik)
}

\author{
Muhammad Bashori Alwi ${ }^{1}$, Said Salim Dahdah ${ }^{2}$, Moh. Jufriyanto ${ }^{3}$ \\ ${ }^{1}$ Mahasiswa Teknik Industri, Fakultas Teknik, Universitas Muhammadiyah Gresik \\ ${ }^{2,3}$ Dosen Teknik Industri, Fakultas Teknik, Universitas Muhammadiyah Gresik Jl. Sumatera No. 101 \\ GKB-Gresik 61121, Jawa Timur, Indonesia \\ E-mail: bashorialwi1999@gmail.com
}

\begin{abstract}
ABSTRAK
Aktivitas penanganan material menyumbang 30\% hingga $40 \%$ dari total biaya produksi. Oleh karena itu bagi sebuah manufaktur untuk menentukan mana sistem penanganan material yang paling cost-effective perlu dilakukan analisis studi kelayakan dari alternatif sistem penanganan material yang akan diinvestasikan untuk sebuah fasilitas. Studi kasus yang diangkat pada makalah ini diambil dari sebuah manufaktur yang bergerak pada produk pupuk. Perusahaan tersebut dihadapkan pada sebuah alternatif investasi proyek belt conveyor dan investasi dump truck. Kedua alternatif tersebut nantinya akan dinilai mana yang paling optimal dari segi biaya yang paling rendah untuk pengangkutan material gipsum curah. Parameter kelayakan investasi yang digunakan adalah Net Present Value (NPV), Internal Rate of Return (IRR), dan Discounted Payback Period (DPP). Dari hasil analisis menunjukkan bahwa pada alternatif investasi proyek belt conveyor memiliki nilai NPV sebanyak $\$ 12.610 .000$, kemudian pada nilai IRR sebesar 45,6\%, dan nilai DPP memiliki durasi selama 4 tahun. Pada alternatif investasi dump truck, nilai NPV sebanyak \$14.135.000, kemudian pada nilai IRR sebesar 52,3\%, dan nilai DPP selama 1 tahun. Tahap selanjutnya, analisis sensitivitas digunakan untuk mengukur seberapa sensitif suatu keputusan terhadap perubahan faktor atau parameter yang mempengaruhi akseptabilitas dari masing-masing alternatif investasi. Dari hasil analisis tersebut dapat disimpulkan bahwa kedua alternatif layak untuk dilakukan meskipun pada skenario terburuk sekalipun.
\end{abstract}

Kata kunci: Belt Conveyor, Dump Truck, Studi Kelayakan

\section{PENDAHULUAN}

Di tengah era globalisasi saat ini, gejolak harga komoditas dan kenaikan biaya operasional yang cukup signifikan memaksa sektor industri manufaktur untuk merancang proses material handling $(\mathrm{MH})$ yang semakin efisien (Almeida et al., 2019). Lebih jauh lagi, telah diketahui secara luas bahwa aktivitas MH menimbulkan biaya non-value added, serta menghabiskan sebagian besar biaya produksi pada keseluruhan, dan berdampak secara nyata pada waktu siklus produk (Tompkins et al. 1996). Biaya aktivitas MH umumnya menyumbang 30\% hingga $40 \%$ dari total biaya produksi (Tompkins, 1984). Namun, poin penting yang terdapat pada sistem MH adalah ia membantu proses produksi. Tanpa sistem MH yang dirancang dengan baik, operasi manufaktur dapat mengalami penundaan (delay), waktu produksi dapat meningkat, produk dapat rusak atau terkontaminasi, dan biaya pergerakan dalam fasilitas dapat meningkat sehingga meningkatkan biaya pengoperasian (Hassan, 2010).

Mengenai aspek ekonomis dari sistem $\mathrm{MH}$, menurut (Ioannou, 1999) identifikasi pemilihan sistem MH yang feasible secara ekonomi untuk meningkatkan produktivitas, merupakan permasalahan yang sangat penting dalam pengambilan keputusan ketika alternatif solusi yang berbeda ditawarkan pada pemilihan beberapa sistem MH. Mengingat perbedaan biaya dan manfaat yang signifikan dapat diperoleh dari penerapan sistem MH yang berbeda. Oleh karena itu, pemilihan sistem MH merupakan fungsi penting dalam desain sistem penanganan material, dengan demikian merupakan sebuah langkah penting dalam perencanaan fasilitas (Chan et al., 2001).

Metode yang akan diadopsi dan pemilihan peralatan untuk sistem $\mathrm{MH}$ sangat bergantung pada jenis bahan yang akan ditangani. Oleh karena itu sangat penting untuk mengetahui berbagai jenis bahan dan karakteristiknya yang berkaitan dengan metode dan sistem $\mathrm{MH}$ yang akan digunakan (Ray, 2008). Pada sistem MH untuk material curah secara khusus, pemilihan sistem MH tergantung pada jarak transportasi, jumlah throughput dan kondisi geografis. Serta hampir semua aktivitas penanganan material curah akan bergantung pada sistem konveyor 
sabuk, truk angkut, atau kereta api, dll (Wheeler, 2019).

Dari beberapa contoh sistem MH curah yang telah disebutkan, bagi sebuah manufaktur untuk menentukan mana sistem MH yang paling costeffective perlu dilakukan analisis studi kelayakan dari alternatif sistem $\mathrm{MH}$ yang akan diinvestasikan untuk sebuah fasilitas. Studi kelayakan memiliki dua pilar utama: investasi yang diperlukan dan manfaat yang diperoleh dari produktivitas sistem (Carrêlo et al., 2020). Mengingat analisis kelayakan investasi dalam pemilihan sistem $\mathrm{MH}$ sangat kompleks, dan ada banyak solusi untuk situasi tertentu (Matson et al., 1992). Hal ini karena pola investasi modal, arus kas pendapatan (atau penghematan), dan arus kas pengeluaran bisa sangat berbeda dalam berbagai proyek, serta tidak ada metode tunggal untuk melakukan analisis studi kelayakan proyek yang ideal untuk semua kasus (Sullivan, 2015).

Selain dilakukan sebelum tahap eksekusi dari sebuah investasi, menurut (Lester, 2017) studi kelayakan investasi harus dilakukan secara berkala sepanjang umur aset untuk memeriksa bahwa dengan perubahan yang tak terhindarkan yang mungkin diperlukan, investasi tersebut masih layak untuk dilanjutkan. Sebagai justifikasi awal kelayakan proyek pada sebuah investasi sistem MH, (Sakka et al., 2020) dan (Dai et al., 2012) mengusulkan beberapa pendekatan pengukuran metrik profitabilitas investasi yang nantinya akan digunakan pada penelitian ini.

Studi kasus yang diangkat pada makalah ini diambil dari sebuah manufaktur yang bergerak pada produk pupuk. Sebagai salah satu produsen pupuk terlengkap di Indonesia, mereka bertanggung jawab untuk memproduksi serta memasok pupuk yang dibutuhkan para petani untuk memperlancar kegiatannya dalam bertani. Seiring dengan perkembangan ilmu pengetahuan dan semakin meningkatnya permintaan akan produk yang dibutuhkan, mereka melakukan riset serta diversivikasi produk untuk memenuhi permintaan konsumen yang beragam. Permintaan produk tersebut tidak hanya datang dari konsumen domestik, namun juga dari mancanegara yang turut serta menggunakan produk yang dihasilkan. Oleh karena itu, mereka tidak hanya memproduksi pupuk untuk petani lokal saja, namun juga produk non-pupuk yang dapat digunakan langsung oleh konsumen maupun perusahaan manufaktur lain sebagai bahan baku atau bahan aditif untuk proses produksinya.
Salah satu dari berbagai produk non-pupuk yang mereka produksi adalah gipsum curah. Material ini merupakan by product yang berasal dari aktivitas reaksi kimia pada saat proses produksi pupuk. Sehingga gipsum bukan merupakan produk utama yang dihasilkan oleh industri tersebut. Walaupun demikian, material gipsum curah tetap memiliki nilai ekonomis bagi manufaktur lain yang membutuhkannya. Melihat prospek keuntungan dari penjualan material gipsum curah bersamaan dengan peningkatan permintaan dari produk tersebut, mereka membutuhkan fasilitas yang lebih memadai untuk mendukung jalannya proses produksi. Salah satu fasilitas yang sedang dibahas pada studi kasus ini adalah sistem $\mathrm{MH}$ untuk kegiatan pemindahan material gipsum curah.

Sebagaimana yang telah disebutkan oleh (Wheeler, 2019) sebelumnya terkait beberapa contoh sistem $\mathrm{MH}$ curah, sistem $\mathrm{MH}$ yang dipertimbangkan untuk transportasi material gipsum curah dalam penelitian ini adalah perbandingan antara moda pengangkutan menggunakan mesin belt conveyor dengan pengangkutan menggunakan dump truck. Secara fungsi, pastinya dua moda tersebut sama-sama untuk memindahkan material dari satu tempat ke tempat lainnya. Namun untuk setiap alternatif, mereka memiliki kelebihan dan kekurangannya masing-masing (Ribeiro et al., 2016).

Tentunya, pengambilan keputusan terkait suatu investasi sistem $\mathrm{MH}$ bukanlah hal yang mudah. Karena pemilihan yang kurang optimal akan menyebabkan biaya produksi yang lebih tinggi (Sevim et al,. 2007). Mengingat jumlah dana yang diinvestasikan untuk sebuah moda pengangkutan tidak sedikit serta risiko investasi yang besar, maka analisis studi kelayakan investasi perlu dilakukan untuk mengidentifikasi biaya-biaya yang terkait, kemudian mengestimasi aliran kas masuk dan aliran kas keluar, serta mengukur profitabilitas investasi selama umur aset dari setiap alternatif moda pengangkutan gipsum curah. Selain itu, pada makalah ini pendekatan analisis sensitivitas juga diterapkan untuk mengukur seberapa sensitif suatu keputusan terhadap perubahan faktor atau parameter yang mempengaruhi akseptabilitas dari masing-masing alternatif investasi.

\section{METODE PENELITIAN}

Dalam penelitian ini, penulis menggunakan beberapa sumber literatur untuk menghimpun data yang relevan terkait dengan studi kasus yang diangkat. Pada umumnya, suatu penelitian terdiri 
dari dua jenis data, yaitu data primer dan data sekunder. Data primer diperoleh dengan cara melakukan observasi langsung pada lokasi penelitian, sedangkan data sekunder diperoleh dari sumber literatur atau hasil penelitian terdahulu yang sesuai dengan topik. Penulis menyadari bahwasannya selama penelitian, data yang diperoleh hanya berasal dari data sekunder. Hal ini dikarenakan penulis memiliki keterbatasan dalam mengakses informasi terkait data primer di perusahaan yang mana bersifat rahasia. Disamping itu, situasi serta kondisi yang kurang memungkinkan bagi penulis untuk melakukan observasi langsung di perusahaan. Namun, penulis berhasil memperoleh beberapa data yang telah dikumpulkan diantaranya:

1. Data jumlah tonase produksi gipsum curah per tahun.

2. Data kondisi aktual dari lokasi proyek.

3. Data jumlah modal investasi yang dibebankan pada masing-masing alternatif.

4. Data estimasi biaya-biaya yang dikeluarkan selama umur aset.

\section{LANGKAH-LANGKAH PENELITIAN}

Langkah - langkah yang dilakukan dalam melakukan penelitian ini adalah sebagai berikut:

1. Studi literatur dan Studi Lapangan

Studi literatur dibutuhkan sebagai dasar serta pijakan dalam menyelesaikan penelitian ini. Literatur yang digunakan yaitu beberapa jurnal dan buku terkait dengan studi kasus kelayakan dari sebuah investasi moda pengangkutan, serta metode perhitungan yang digunakan untuk mengukur provitabilitas investasi. Studi lapangan yang dilakukan yaitu wawancara dengan narasumber dari pihak perusahaan untuk mendapatkan gambaran aktual dari proyek yang akan dilaksanakan.

2. Pengumpulan Data

Pada penelitian ini, dilakukan pengumpulan data yaitu data primer dan data sekunder.

a. Data primer merupakan data hasil wawancara yang terdiri dari site plan proyek, alternatif moda pengangkutan yang akan digunakan, jumlah tonase produksi gipsum curah per tahun.

b. Data sekunder merupakan data yang diperoleh dari penelitian terdahulu berupa komponen modal investasi serta estimasi biaya yang dikeluarkan selama horizon perencanaan dari suatu aset.

3. Pengolahan Data

a. Mendefinisikan kondisi aktual dari permasalahan yang diangkat sesuai dengan hasil wawancara. Kemudian menentukan beberapa asumsi yang dibutuhkan untuk mempermudah dalam pemilihan alternatif moda pengangkutan material gipsum curah.

b. Menentukan desain optimal dari setiap moda pengangkutan berdasarkan sumber literatur serta asumsi yang telah ditetapkan.

c. Menentukan biaya investasi yang dibutuhkan, kemudian mengestimasikan aliran kas yang dikeluarkan selama aset beroperasi.

d. Melakukan analisis komparatif profitabilitas investasi menggunakan metode yang diusulkan pada setiap alternatif moda pengangkutan gipsum curah.

e. Menguji tingkat sensitivitas dari perubahan parameter yang mungkin terjadi, serta mengukur sejauh mana perubahan tersebut dalam mempengaruhi pengambilan keputusan investasi.

Pada penelitian ini, metode justifikasi awal dari investasi yang digunakan berdasarkan penelitian yang telah dilakukan oleh (Sakka et al., 2020) dan (Dai \& Lee, 2012). Metode tersebut diantaranya adalah:

a. Net Present Value (NPV)

Metode NPV didasarkan pada konsep nilai ekuivalen dari semua arus kas relatif terhadap suatu dasar atau titik awal dalam waktu yang disebut masa sekarang. Artinya, semua arus masuk dan arus kas keluar didiskontokan hingga saat ini pada tingkat bunga yang umumnya adalah MARR (Sullivan, 2015).

$$
N P V(i \%)=\sum_{k=0}^{N} F_{k}(1+i)^{-k}
$$

i Suku bunga efektif, atau MARR, per $=$ periode majemuk

$\mathrm{k}=$ Indeks untuk setiap periode penggandaan $(0 \leq \mathrm{k} \leq \mathrm{N})$

$F_{k}=$ Arus kas masa depan pada akhir periode $k$

$N=$ Jumlah periode perencanaan

b. Internal Rate of Return (IRR)

Metode ini menentukan tingkat bunga yang menyamakan nilai yang setara dari arus kas masuk alternatif (penerimaan atau penghematan) dengan nilai yang setara dari arus kas keluar (pengeluaran, termasuk biaya investasi) (Hedianto et al., 2019).

$$
\sum_{k=0}^{N} R_{k}\left(\frac{P}{F}, i \%, k\right)=\sum_{k=0}^{N} E_{k}\left(\frac{P}{F}, i \%, k\right)
$$

$R_{k}=$ Pendapatan bersih atau penghematan untuk tahun ke-k

$E_{k}=$ Pengeluaran bersih, termasuk biaya 


\section{investasi untuk tahun ke-k \\ $N \quad$ Jumlah periode perencanaan $=$}

c. Discounted Payback Period (DPP)

Metode Discounted PBP menghitung jumlah tahun yang dibutuhkan agar arus kas masuk sama dengan arus kas keluar (Sullivan, 2015).

$$
\sum_{k=1}^{\theta^{\prime}}\left(R_{k}-E_{k}\right)\left(\frac{P}{F}, i \%, k\right)-I \geq 0
$$

$\mathrm{i} \%=$ Tingkat MARR yang digunakan

$\theta^{\prime} \quad$ Nilai terkecil yang memenuhi

$=$

$\mathrm{I}=$ Jumlah modal investasi pada $\mathrm{k}=0$

\section{HASIL DAN PEMBAHASAN}

\subsection{Kondisi Aktual}

Material curah kering homogen seperti bijih besi, batu bara, gipsum dapat ditangani dengan sangat efisien menggunakan terminal singlepurpose (Stopford, 2009). Rencananya setelah melalui tahapan produksi pada pabrik, material gypsum curah akan disimpan sementara pada sebuah lapangan khusus yang disebut disposal. Dalam hal ini, disposal berperan sebagai penyangga antara pabrik produksi dengan terminal, serta memastikan terminal memiliki material yang cukup untuk dimuat ke kapal saat mereka tiba. Karena jika material tidak mencukupi, atau proses transportasi material yang lama, kongesti akan terjadi karena kapal menunggu untuk memuat material. Kemudian terminal berfungsi sebagai tempat bersandar kapal kargo curah untuk proses pemuatan material.

kegiatan transportasi material gipsum curah berawal dari disposal dimana tempat material ditimbun, hingga terminal baru yang dibangun khusus untuk pemuatan material gipsum curah ke kapal dengan kapasitas maksimal 10.000 DWT. Setelah proses reclaiming dari disposal selesai, material nantinya dapat diangkut melalui dua moda alternatif pengangkutan sebagaimana yang telah dijelaskan di bagian sebelumnya.

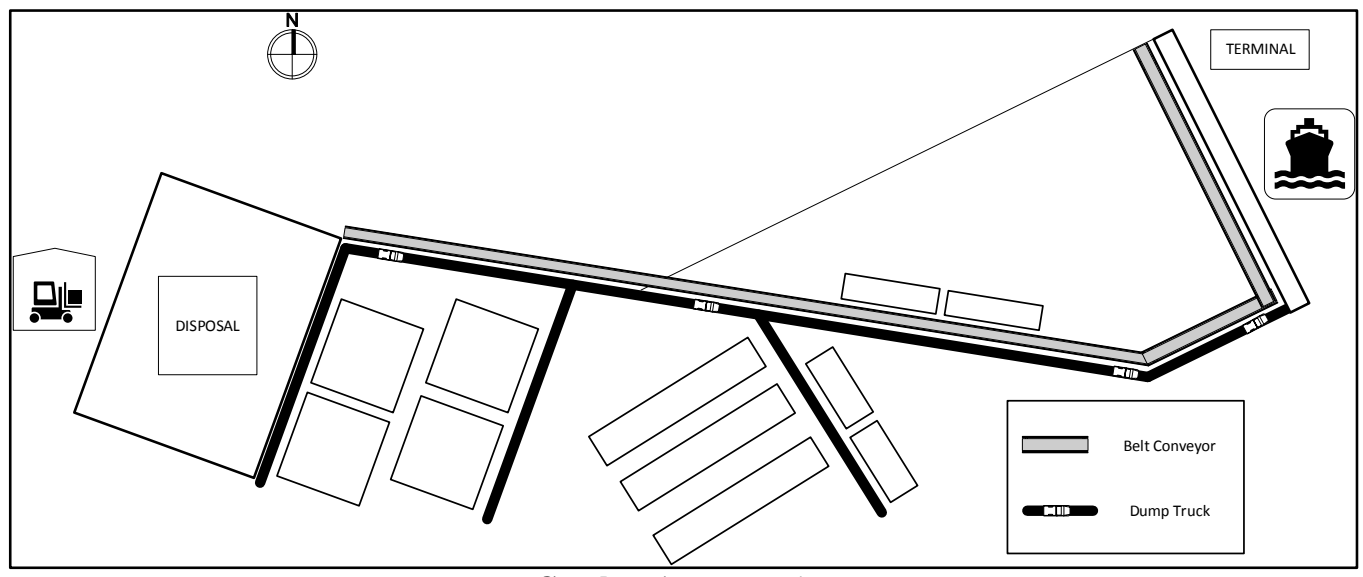

Gambar 1 Layout Plan

Berdasarkan pada gambar 1, menunjukkan rute dari setiap alternatif moda pengangkutan. Ditinjau dari infrastruktur dan geografis pada lokasi penelitian, untuk mengadopsi salah satu alternatif moda pengangkutan dapat dilakukan sesuai dengan rencana. Hal ini karena terdapat beberapa infrastruktur yang sebelumnya telah dibangun oleh perusahaan serta kondisi dataran landai yang dapat mendukung operasional dari masing-masing alternatif. Misalkan apabila perusahaan memustuskan untuk menggunakan pengangkutan dump truck, hal tersebut dimungkinkan karena perusahaan telah membangun infrastruktur jalan aspal sebagai sarana transportasi internal antara pabrik produksi. Sehubungan dengan keterbatasan peneliti dalam melakukan observasi langsung, diasumsikan bahwa transportasi dump truck dari disposal ke terminal memiliki jarak sejauh 2,4 kilometer.

Pada sisi lain apabila sistem belt conveyor dipertimbangkan sebagai alternatif moda pengangkutan yang optimum, maka proyek konstruksi pembangunan dapat langsung dieksekusi. Berdasarkan hasil wawancara, dapat diketahui bahwa mesin belt conveyor nantinya akan dibangun di atas daratan hasil reklamasi, dimana daratan tersebut juga sekaligus berfungsi sebagai terminal (jetty) yang khusus dibangun untuk pemuatan material gipsum curah ke kapal. Mesin belt conveyor akan membentang sepanjang 2,4 kilometer, dimana angka estimasi 
tersebut diperoleh melalui pengukuran secara virtual oleh peneliti.

Sebelum memperoleh desain yang optimal dari masing-masing alternatif moda pengangkutan material gipsum curah, perlu diketahui rencana jumlah produksi per tahunnya. Berdasarkan laporan tahunan, dapat diasumsikan rata-rata produksi gypsum curah adalah 500.000 ton per tahunnya. Sehingga untuk memenuhi rencana produksi tersebut, setiap kapasitas alternatif moda transportasi harus dirancang sesuai dengan target. Selain itu, diasumsikan selama satu tahun kalender kedua moda transportasi hanya beroperasi pada saat kapal bersandar, dengan durasi setiap kegiatan pemuatan material berdasarkan kesepakatan laytime antara penyewa dengan pemilik kapal.

\subsection{Sistem Belt Conveyor}

Sistem belt conveyor akan dibangun dari disposal ke terminal seperti yang ditunjukkan pada Gambar 1. Pada proses pemodelan sistem belt conveyor yang optimal, dalam penelitian ini penulis mengandalkan beberapa studi literatur yang relevan dengan proses pengangkutan material curah. Mengacu pada Conveyor Equipment Manufacturers Association (CEMA, 2002), desain belt conveyor yang sukses harus dimulai dengan penilaian yang akurat terkait karakteristik material yang akan diangkut. Perlu diperhatikan fakta bahwa karakteristik material sangat mempengaruhi pergerakan, kemiringan, dan kecepatan belt conveyor yang membawanya. Dalam hal ini material gipsum curah diklasifikasikan sebagai material serbuk yang halus dan berdebu. Sehingga belt conveyor harus dilengkapi dengan belt, idler, pulleys, shafts, gravity take-up, hood penutup setengah, serta unit penggerak dengan gear reducer (CEMA, 2002). Disamping itu desain belt conveyor dilengkapi variabel frekwensi yang fleksibel, sehingga mampu beroperasi pada beberapa variasi kecepatan. Hal ini memungkinkan belt conveyor bekerja pada kapasitas tertentu sesuai kebutuhan tingkat troughput per jamnya.

Setelah mengetahui karakteristik material tersebut, penulis merangkum spesifikasi standar belt conveyor berdasarkan beberapa penelitian yang sama. Data input untuk sistem belt conveyor diberikan pada tabel 1 .

Tabel 1 Data Masukan Sistem Belt Conveyor

\begin{tabular}{|c|c|c|}
\hline Komponen & Satuan & Referensi \\
\hline Lebar belt & 55 inch & $\begin{array}{c}\text { (Masaki et al., } \\
\text { 2017) }\end{array}$ \\
\hline
\end{tabular}

\begin{tabular}{|c|c|c|}
\hline $\begin{array}{l}\text { Kecepatan } \\
\text { belt }\end{array}$ & $2,3 \mathrm{~m} / \mathrm{s}$ & $\begin{array}{c}\text { (Sevim \& } \\
\text { Sharma, 1991) }\end{array}$ \\
\hline Panjang belt & $5000 \mathrm{~m}$ & Asumsi \\
\hline $\begin{array}{l}\text { Troughing } \\
\text { angle }\end{array}$ & $35^{0}$ & $\begin{array}{c}\text { (Sevim \& } \\
\text { Sharma, 1991) }\end{array}$ \\
\hline $\begin{array}{l}\text { Surcharge } \\
\text { angle }\end{array}$ & $5^{0}$ & $\begin{array}{c}\text { (CEMA, } \\
2002)\end{array}$ \\
\hline $\begin{array}{c}\text { Availability } \\
\text { dari sistem }\end{array}$ & $95 \%$ & $\begin{array}{c}\text { (Rudianto \& } \\
\text { Hartanto, } \\
\text { 2020) }\end{array}$ \\
\hline Umur belt & 7 tahun & $\begin{array}{c}(\text { Sevim \& } \\
\text { Sharma, 1991) }\end{array}$ \\
\hline $\begin{array}{c}\text { Biaya } \\
\text { perbaikan } \\
\text { dan } \\
\text { perawatan }\end{array}$ & $\begin{array}{c}5 \% \text { untuk belt dan } \\
2 \% \text { untuk } \\
\text { komponen lain } \\
\text { dari biaya modal }\end{array}$ & $\begin{array}{c}(\text { Sevim \& } \\
\text { Sharma, 1991) }\end{array}$ \\
\hline $\begin{array}{c}\text { Biaya } \\
\text { instalasi }\end{array}$ & $\begin{array}{c}30 \% \text { dari biaya } \\
\text { modal }\end{array}$ & $\begin{array}{c}(\text { Sevim \& } \\
\text { Sharma, 1991) }\end{array}$ \\
\hline $\begin{array}{l}\text { Peralatan } \\
\text { kontrol, } \\
\text { kabel listrik, } \\
\text { starter } \text { dll }\end{array}$ & $\begin{array}{l}10 \% \text { dari biaya } \\
\text { modal }\end{array}$ & $\begin{array}{c}(\text { Sevim \& } \\
\text { Sharma, 1991) }\end{array}$ \\
\hline Tipe drive & Dual & $\begin{array}{c}\text { (CEMA, } \\
\text { 2002) }\end{array}$ \\
\hline $\begin{array}{l}\text { Motor } 1 \\
\text { (primer) }\end{array}$ & $298 \mathrm{Kw}$ & $\begin{array}{c}\text { (CEMA, } \\
\text { 2002) }\end{array}$ \\
\hline $\begin{array}{c}\text { Motor } 2 \\
\text { (sekunder) }\end{array}$ & $75 \mathrm{Kw}$ & $\begin{array}{c}\text { (CEMA, } \\
\text { 2002) }\end{array}$ \\
\hline $\begin{array}{c}\text { Total wrap } \\
\text { angle }\end{array}$ & $\begin{array}{c}240^{\circ} \text { untuk setiap } \\
\text { drive }\end{array}$ & $\begin{array}{c}\text { (Masaki et al., } \\
\text { 2017) }\end{array}$ \\
\hline $\begin{array}{c}\text { Jarak spasi } \\
\text { dan jenis } \\
\text { idler (Carry) }\end{array}$ & $\begin{array}{c}\text { 1,2 m; CEMA } \\
\text { Class C }\end{array}$ & $\begin{array}{c}\text { (CEMA, } \\
\text { 2002) }\end{array}$ \\
\hline $\begin{array}{c}\text { Jarak spasi } \\
\text { dan jenis } \\
\text { idler } \\
\text { (return) }\end{array}$ & $\begin{array}{c}3 \mathrm{~m} \text {; CEMA Class } \\
\mathrm{C}\end{array}$ & $\begin{array}{c}\text { (CEMA, } \\
\text { 2002) }\end{array}$ \\
\hline Jenis belt & Steelcord belt & $\begin{array}{c}\text { (Masaki et al., } \\
\text { 2017) }\end{array}$ \\
\hline $\begin{array}{l}\text { Project } \\
\text { lifetime }\end{array}$ & 20 tahun & $\begin{array}{c}\text { (Masaki et al., } \\
\text { 2017) }\end{array}$ \\
\hline Operator & 2 orang / shift & Asumsi \\
\hline
\end{tabular}

Sehubungan dengan keterbatasan peneliti dalam melakukan observasi langsung pada perusahaan, data komponen biaya untuk investasi sistem belt conveyor dikumpulkan dari penelitian yang telah dilakukan oleh (Sevim \& Sharma, 1991), kemudian nilai uang telah dikonversikan ke tahun saat penelitian ini ditulis. Dalam hal ini, diasumsikan bahwa untuk komponen belt diganti setiap 7 tahun sekali yang disebabkan oleh gesekan selama mesin digunakan. Sedangkan untuk biaya operasi yang dikeluarkan setiap tahunnya, penulis mengasumsikan terdiri dari biaya untuk kebutuhan listrik, perawatan, dan tenaga kerja. Disamping itu pula diasumsikan tidak terjadi eskalasi biaya operasi setiap 
tahunnya. Detail biaya modal investasi dan biaya

perencanaan

selama

20

tahun. operasi dapat dilihat pada tabel 2 dengan horizon

Tabel 2 Estimasi Aliran Kas Sistem Belt Conveyor (Dalam Ribuan Dollar Amerika)

\begin{tabular}{|c|c|c|c|c|c|c|c|c|c|c|c|c|c|c|c|c|c|c|c|c|c|}
\hline Year & 0 & 1 & 2 & 3 & 4 & 5 & 6 & 7 & 8 & 9 & 10 & 11 & 12 & 13 & 14 & 15 & 16 & 17 & 18 & 19 & 20 \\
\hline \multicolumn{22}{|l|}{ Capital Investment } \\
\hline Belt & 2705 & & & & & & & 2705 & & & & & & & 2705 & & & & & & \\
\hline Idler & 984 & & & & & & & & & & & & & & & & & & & & \\
\hline Deck & 1988 & & & & & & & & & & & & & & & & & & & & \\
\hline Hood & 608 & & & & & & & & & & & & & & & & & & & & \\
\hline Motor \& reducer & 554 & & & & & & & & & & & & & & & & & & & & \\
\hline Pulleys, shaft, pillow blocks & 1036 & & & & & & & & & & & & & & & & & & & & \\
\hline Control, wiring, starters & 889 & & & & & & & & & & & & & & & & & & & & \\
\hline Erection \& installation & 2629 & & & & & & & & & & & & & & & & & & & & \\
\hline \multicolumn{22}{|l|}{ Operating Cost } \\
\hline Repair \& Maintenance & & 256 & 256 & 256 & 256 & 256 & 256 & 256 & 256 & 256 & 256 & 256 & 256 & 256 & 256 & 256 & 256 & 256 & 256 & 256 & 256 \\
\hline Power & & 239 & 239 & 239 & 239 & 239 & 239 & 239 & 239 & 239 & 239 & 239 & 239 & 239 & 239 & 239 & 239 & 239 & 239 & 239 & 239 \\
\hline Labor & & 154 & 154 & 154 & 154 & 154 & 154 & 154 & 154 & 154 & 154 & 154 & 154 & 154 & 154 & 154 & 154 & 154 & 154 & 154 & 154 \\
\hline Total cash flow & 11393 & 649 & 649 & 649 & 649 & 649 & 649 & 3354 & 649 & 649 & 649 & 649 & 649 & 649 & 3354 & 649 & 649 & 649 & 649 & 649 & 649 \\
\hline
\end{tabular}

\subsection{Pengangkutan Dump Truck}

Berdasarkan hasil wawancara, dump truck yang digunakan oleh perusahaan memiliki tonase berat kotor 30 ton, dengan konfigurasi sumbu roda yaitu $6 \times 4$. Dalam studi ini, dump truck akan menempuh jarak transportasi sejauh 2,4 kilometer dari disposal hingga terminal.

Menurut (Ribeiro et al., 2016), dump truck memiliki beberapa kelebihan diantaranya adalah fleksibilitas dan multi-purpose. Namun usia pakai dump truck relatif lebih singkat daripada alternatif sebelumnya yang dibahas pada penelitian ini. Mengingat hal tersebut, perusahaan akan lebih sering mengganti armada truk lama dengan yang baru. Disamping itu jumlah truk yang akan diinvestasikan harus dipertimbangkan. Karena jika terlalu banyak, akan mengakibatkan kemacetan lalu lintas internal yang dapat mengganggu kelancaran transportasi material. Sebaliknya, jika armada tidak mencukupi akan menyebabkan keterlambatan yang dapat berujung demurrage. Oleh karena itu dalam penentuan jumlah dump truck yang diinvestasikan, penulis mengadaptasikan dari penelitian (Shakantu et al., 2012) yaitu sebanyak 25 armada truk. Kemudian berdasarkan website resmi, harga on the road masing-masing truk sebesar 900 juta rupiah.

Setelah diketahui gambaran singkat dari dump truck yang akan diinvestasikan, berikut pada tabel 3 menyajikan data input yang telah peneliti kumpulkan dari beberapa sumber.

Tabel 3 Data Masukan Dump Truck

\begin{tabular}{|c|c|c|}
\hline Parameter & Satuan & Referensi \\
\hline $\begin{array}{c}\text { Berat } \\
\text { kosong }\end{array}$ & $6490 \mathrm{~kg}$ & Website resmi \\
\hline Berat kotor & $30000 \mathrm{~kg}$ & Website resmi \\
\hline Jumlah truk & 25 & (Shakantu et \\
\hline
\end{tabular}

\begin{tabular}{|c|c|c|}
\hline $\begin{array}{c}\text { Harga } \\
\text { OTR/unit }\end{array}$ & $\$ 64.000$ & Website resmi \\
\hline $\begin{array}{c}\text { Jarak } \\
\text { transportasi }\end{array}$ & $2400 \mathrm{~m}$ & Asumsi \\
\hline $\begin{array}{c}\text { Umur } \\
\text { pemakaian }\end{array}$ & 6 tahun & $\begin{array}{c}\text { (Marufuzzaman } \\
\text { et al., 2015) }\end{array}$ \\
\hline $\begin{array}{c}\text { Jarak } \\
\text { tempuh } \\
\text { setiap truk } \\
\text { per tahun }\end{array}$ & $75.000 \mathrm{~km}$ & Asumsi \\
\hline $\begin{array}{c}\text { Biaya } \\
\text { perbaikan } \\
\text { dan } \\
\text { perawatan }\end{array}$ & $\$ 0,1 / \mathrm{km}$ & $\begin{array}{c}\text { (Sdoukopoulos } \\
\text { et al., 2015) }\end{array}$ \\
\hline $\begin{array}{c}\text { Biaya bahan } \\
\text { bakar }\end{array}$ & $\$ 0,27 / \mathrm{km}$ & $\begin{array}{c}\text { (Engholm et } \\
\text { al., 2020) }\end{array}$ \\
\hline $\begin{array}{c}\text { Biaya } \\
\text { penggantian } \\
\text { ban }\end{array}$ & $\$ 0,023 / \mathrm{km}$ & $\begin{array}{c}\text { (Hang et al., } \\
\text { 2016) }\end{array}$ \\
\hline $\begin{array}{c}\text { Biaya } \\
\text { asuransi }\end{array}$ & $\$ 0,052 / \mathrm{km}$ & $\begin{array}{c}\text { (Marufuzzaman } \\
\text { et al., 2015) }\end{array}$ \\
\hline $\begin{array}{c}\text { Biaya } \\
\text { pengemudi }\end{array}$ & $\$ 0,37 / \mathrm{km}$ & $\begin{array}{c}\text { (Engholm et } \\
\text { al., 2020) }\end{array}$ \\
\hline
\end{tabular}

Mengingat peneliti tidak dapat melakukan observasi secara langsung melainkan hanya berdasarkan pada penelitian sebelumnya, sehingga beberapa studi mengenai estimasi biaya transportasi dump truck diadaptasikan pada studi kasus ini. Sebagaimana yang ditunjukkan pada tabel 4, menggambarkan detail biaya yang dikeluarkan selama horizon perencanaan 20 tahun. Penggantian truk baru dilakukan setiap 6 tahun sekali sesuai dengan umur ekonomisnya. Kemudian untuk biaya operasi terdiri dari asuransi, perbaikan dan perawatan, biaya pengemudi, biaya bahan bakar, dan biaya penggantian ban. 
Tabel 4 Estimasi Aliran Kas Sistem Dump Truck (Dalam Ribuan Dollar Amerika)

\begin{tabular}{|c|c|c|c|c|c|c|c|c|c|c|c|c|c|c|c|c|c|c|c|c|c|}
\hline Tahun & 0 & 1 & 2 & 3 & 4 & 5 & 6 & 7 & 8 & 9 & 10 & 11 & 12 & 13 & 14 & 15 & 16 & 17 & 18 & 19 & 20 \\
\hline \multicolumn{22}{|l|}{\begin{tabular}{|l|} 
Modal Investasi \\
\end{tabular}} \\
\hline Dump Truck & 4782 & & & & & & \begin{tabular}{|c|}
4782 \\
\end{tabular} & & & & & & 4782 & & & & & & 4782 & & \\
\hline Bengkel \& garasi & 2345 & & & & & & & & & & & & & & & & & & & & \\
\hline Wheel Loader & 959 & & & & & 959 & & & & & \begin{tabular}{|l|l}
959 \\
\end{tabular} & & & & & \begin{tabular}{|c|c|}
959 \\
\end{tabular} & & & & & \\
\hline \multicolumn{22}{|l|}{\begin{tabular}{|l} 
Biaya Operasi \\
\end{tabular}} \\
\hline Asuransi & & 78 & 78 & 78 & 78 & 78 & 78 & 78 & 78 & 78 & 78 & 78 & 78 & 78 & 78 & 78 & 78 & 78 & 78 & 78 & 78 \\
\hline Perbaikan \& perawata & & 150 & 150 & 150 & 150 & 150 & 150 & 150 & 150 & 150 & 150 & 150 & 150 & 150 & 150 & 150 & 150 & 150 & 150 & 150 & 150 \\
\hline Pengemudi truk & & 555 & 555 & 555 & 555 & 555 & 555 & \begin{tabular}{|l|l}
555 \\
\end{tabular} & 555 & 555 & \begin{tabular}{|l|l}
555 \\
\end{tabular} & 555 & 555 & \begin{tabular}{|l|l}
555 \\
\end{tabular} & \begin{tabular}{|l|l}
555 \\
\end{tabular} & 555 & 555 & 555 & 555 & 555 & 555 \\
\hline Bahan bakar & & 405 & 405 & 405 & 405 & 405 & 405 & 405 & 405 & 405 & 405 & 405 & 405 & 405 & 405 & 405 & 405 & 405 & 405 & 405 & 405 \\
\hline Penggantian ban & & 35 & 35 & 35 & 35 & 35 & 35 & 35 & 35 & 35 & 35 & 35 & 35 & 35 & 35 & 35 & 35 & 35 & 35 & 35 & 35 \\
\hline \begin{tabular}{|l} 
Total Aliran Kas \\
\end{tabular} & 8086 & 1223 & 1223 & 1223 & 1223 & \begin{tabular}{|l|l}
2182 \\
\end{tabular} & 6005 & \begin{tabular}{|l|l|}
1223 \\
\end{tabular} & \begin{tabular}{|l|l|}
1223 \\
\end{tabular} & 1223 & \begin{tabular}{|l|l|}
2182 \\
\end{tabular} & 1223 & 6005 & 1223 & 1223 & 2182 & \begin{tabular}{l|l|}
1223 \\
\end{tabular} & \begin{tabular}{l|l|}
1223 \\
\end{tabular} & 6005 & 1223 & 1223 \\
\hline
\end{tabular}

\subsection{Hasil Studi Kelayakan Ekonomis}

Fase selanjutnya adalah proses pengambilan keputusan investasi setelah selesai mendefinisikan alternatif-alternatif yang dipertimbangkan dalam penelitian ini. Mengingat sumber daya maupun kemampuan perusahaan yang terbatas dalam mengambil kedua alternatif, maka pemilihan satu alternatif akan mengakibatkan penolakan pada alternatif lainnya. Sehingga dalam hal ini pengambilan keputusan bersifat mutually exclusive.

Pada makalah ini, peneliti menetapkan perbandingan alternatif investasi memiliki periode studi selama 20 tahun untuk menggambarkan sejauh mana kedepannya cash flow masih akan dipertimbangkan dalam analisis. Kemudian dikarenakan umur teknis antara belt conveyor dengan dump truck yang berbeda, maka analisis deret seragam digunakan untuk menilai kelayakan dari investasi selama horizon perencanaan. Deret seragam yang dimaksud dalam hal ini adalah pengeluaran dan pemasukan tetap pada setiap tahunnya. Dimana aliran kas keluar sebagaimana yang ditunjukkan pada tabel 2 dan 4, sedangkan aliran kas masuk merupakan pendapatan hasil penjualan per tahun. Berdasarkan harga pasar yang tecantum pada situs $e$-commerce, diasumsikan harga jual gipsum curah sebesar $\$ 15$ / ton.

Tabel 5 menunjukkan data masukan dalam pemilihan alternatif investasi belt conveyor dan dump truck. Selanjutnya pada tabel 6 dan 7 menunjukkan hasil analisis aliran kas setelah pajak untuk masing-masing alternatif. Kemudian dari hasil analisis tersebut digunakan untuk mengevaluasi kinerja ekonomis sebagaimana yang terdapat pada tabel 8 .
Tabel 5 Data Masukan Pemilihan Alternatif Investasi

\begin{tabular}{|l|l|l|}
\hline $\begin{array}{l}\text { Data } \\
\text { Masukan }\end{array}$ & $\begin{array}{l}\text { Belt } \\
\text { Conveyor }\end{array}$ & Dump Truck \\
\hline Modal awal & $\$ 11,393$ Juta & $\$ 8,086$ Juta \\
\hline $\begin{array}{l}\text { Pemasukan } \\
\text { tahunan }\end{array}$ & $\$ 7.500 .000$ & $\$ 7.500 .000$ \\
\hline $\begin{array}{l}\text { Pajak } \\
\text { pendapatan }\end{array}$ & $25 \%$ & $25 \%$ \\
\hline MARR & $20 \%$ & $20 \%$ \\
\hline Nilai sisa & $\$ 980.000$ & $\$ 210.000$ \\
\hline $\begin{array}{l}\text { Metode } \\
\text { depresiasi }\end{array}$ & Garis lurus & Garis lurus \\
\hline
\end{tabular}

Tabel 6 Aliran Kas Setelah Pajak Sistem Belt Conveyor (Dalam Ribuan Dollar Amerika)

\begin{tabular}{|c|c|c|c|c|c|}
\hline Year & BTCF & Depreciation & $\begin{array}{c}\text { Taxable } \\
\text { Income }\end{array}$ & $\begin{array}{c}\text { Income } \\
\text { Tax }\end{array}$ & ATCF \\
\hline 0 & -11393 & & & & -11393 \\
\hline 1 & 6931 & 521 & 6410 & 1602 & 5328 \\
\hline 2 & 6931 & 521 & 6410 & 1602 & 5328 \\
\hline 3 & 6931 & 521 & 6410 & 1602 & 5328 \\
\hline 4 & 6931 & 521 & 6410 & 1602 & 5328 \\
\hline 5 & 6931 & 521 & 6410 & 1602 & 5328 \\
\hline 6 & 6931 & 521 & 6410 & 1602 & 5328 \\
\hline 7 & 4226 & 521 & 3705 & 926 & 3299 \\
\hline 8 & 6931 & 521 & 6410 & 1602 & 5328 \\
\hline 9 & 6931 & 521 & 6410 & 1602 & 5328 \\
\hline 10 & 6931 & 521 & 6410 & 1602 & 5328 \\
\hline 11 & 6931 & 521 & 6410 & 1602 & 5328 \\
\hline 12 & 6931 & 521 & 6410 & 1602 & 5328 \\
\hline 13 & 6931 & 521 & 6410 & 1602 & 5328 \\
\hline 14 & 4226 & 521 & 3705 & 926 & 3299 \\
\hline 15 & 6931 & 521 & 6410 & 1602 & 5328 \\
\hline 16 & 6931 & 521 & 6410 & 1602 & 5328 \\
\hline 17 & 6931 & 521 & 6410 & 1602 & 5328 \\
\hline 18 & 6931 & 521 & 6410 & 1602 & 5328 \\
\hline 19 & 6931 & 521 & 6410 & 1602 & 5328 \\
\hline 20 & 7911 & 521 & 7390 & 1847 & 6063 \\
\hline & & & & & \\
\hline
\end{tabular}


Tabel 7 Aliran Kas Setelah Pajak Sistem Dump Truck (Dalam Ribuan Dollar Amerika)

\begin{tabular}{|c|c|c|c|c|c|}
\hline Year & BTCF & Depreciation & $\begin{array}{c}\text { Taxable } \\
\text { Income }\end{array}$ & $\begin{array}{c}\text { Income } \\
\text { Tax }\end{array}$ & ATCF \\
\hline 0 & -8086 & & & & -8086 \\
\hline 1 & 6138 & 394 & 5744 & 1436 & 4702 \\
\hline 2 & 6138 & 394 & 5744 & 1436 & 4702 \\
\hline 3 & 6138 & 394 & 5744 & 1436 & 4702 \\
\hline 4 & 6138 & 394 & 5744 & 1436 & 4702 \\
\hline 5 & 6138 & 394 & 5744 & 1436 & 4702 \\
\hline 6 & 4859 & 394 & 4465 & 1116 & 3743 \\
\hline 7 & 6138 & 394 & 5744 & 1436 & 4702 \\
\hline 8 & 6138 & 394 & 5744 & 1436 & 4702 \\
\hline 9 & 6138 & 394 & 5744 & 1436 & 4702 \\
\hline 10 & 6138 & 394 & 5744 & 1436 & 4702 \\
\hline 11 & 6138 & 394 & 5744 & 1436 & 4702 \\
\hline 12 & 4859 & 394 & 4465 & 1116 & 3743 \\
\hline 13 & 6138 & 394 & 5744 & 1436 & 4702 \\
\hline 14 & 6138 & 394 & 5744 & 1436 & 4702 \\
\hline 15 & 6138 & 394 & 5744 & 1436 & 4702 \\
\hline 16 & 6138 & 394 & 5744 & 1436 & 4702 \\
\hline 17 & 6138 & 394 & 5744 & 1436 & 4702 \\
\hline 18 & 4859 & 394 & 4465 & 1116 & 3743 \\
\hline 19 & 6138 & 394 & 5744 & 1436 & 4702 \\
\hline 20 & 6348 & 394 & 5954 & 1489 & 4860 \\
\hline
\end{tabular}

Tabel 8 Hasil Studi Kelayakan Ekonomi

\begin{tabular}{|l|l|l|}
\hline Parameter & $\begin{array}{l}\text { Belt } \\
\text { Conveyor }\end{array}$ & Dump Truck \\
\hline NPV & $\$ 12.610 .000$ & $\$ 14.135 .000$ \\
\hline IRR & $45,6 \%$ & $52,3 \%$ \\
\hline DPP & 4 tahun & 1 tahun \\
\hline
\end{tabular}

Berdasarkan tabel 8 menunjukkan bahwa kedua alternatif layak untuk diinvestasikan. Karena ditinjau dari nilai IRR-nya yang lebih besar dari MARR pada masing-masing alternatif. Disamping itu, masa pengembalian modal yang dikeluarkan pada tahun ke-0 untuk setiap alternatif menunjukkan lebih cepat dari umur ekonomisnya. Namun jika mengacu pada net present value, alternatif belt conveyor terbukti lebih rendah daripada dump truck.

\subsection{Analisis Sensitivitas}

Terdapat beberapa masalah yang berpotensi mengganggu estimasi untuk studi kelayakan ekonomi. Pertama, biaya mungkin terlalu tinggi atau terlalu rendah meskipun telah dibandingkan dengan biaya investasi sistem yang serupa. Selain itu, kemungkinan akan ada biaya tambahan yang harus dikeluarkan yang tidak diperkirakan sebelumnya, terutama dalam kegiatan operasi atau pemeliharaan sistem tersebut. Oleh karena itu, analisis sensitivitas pada sebuah investasi diperlukan untuk mengeksplorasi apa yang terjadi pada profitabilitas investasi ketika perkiraan nilai faktor studi dirubah.

Empat variabel relevan telah ditentukan untuk melakukan analisis sensitivitas pada masingmasing alternatif investasi. Pada investasi proyek belt conveyor terdiri dari variabel biaya proyek, biaya operator, biaya repair \& maintenanance, dan biaya listrik. Kemudian pada pengangkutan dump truck terdiri dari biaya pembelian, biaya pengemudi, biaya repair \& maintenanance, serta biaya bahan bakar.

Tabel 9 Skenario Analisis Sensitivitas Sistem Belt Conveyor (Dalam Ribuan Dollar Amerika)

\begin{tabular}{|l|c|c|c|}
\hline \multicolumn{4}{|c|}{ Belt Conveyor } \\
\hline NPV & Worst $(+25 \%)$ & Base & Best $(-25 \%)$ \\
\hline P. Cost & $\$ 14.982$ & $\$ 12.610$ & $\$ 8.545$ \\
\hline Labor & $\$ 12.764$ & $\$ 12.610$ & $\$ 12.452$ \\
\hline R\&M & $\$ 12.868$ & $\$ 12.610$ & $\$ 12.348$ \\
\hline Power & $\$ 12.769$ & $\$ 12.610$ & $\$ 12.447$ \\
\hline
\end{tabular}

Tabel 10 Skenario Analisis Sensitivitas Sistem Dump Truck (Dalam Ribuan Dollar Amerika)

\begin{tabular}{|l|c|c|c|}
\hline \multicolumn{4}{|c|}{ Dump Truck } \\
\hline NPV & Worst $(+25 \%)$ & Base & Best $(-25 \%)$ \\
\hline P. Cost & $\$ 15.819$ & $\$ 14.135$ & $\$ 12.450$ \\
\hline Driver & $\$ 14.698$ & $\$ 14.135$ & $\$ 13.572$ \\
\hline R\&M & $\$ 14.287$ & $\$ 14.135$ & $\$ 13.982$ \\
\hline Fuel & $\$ 14.545$ & $\$ 14.135$ & $\$ 13.724$ \\
\hline
\end{tabular}

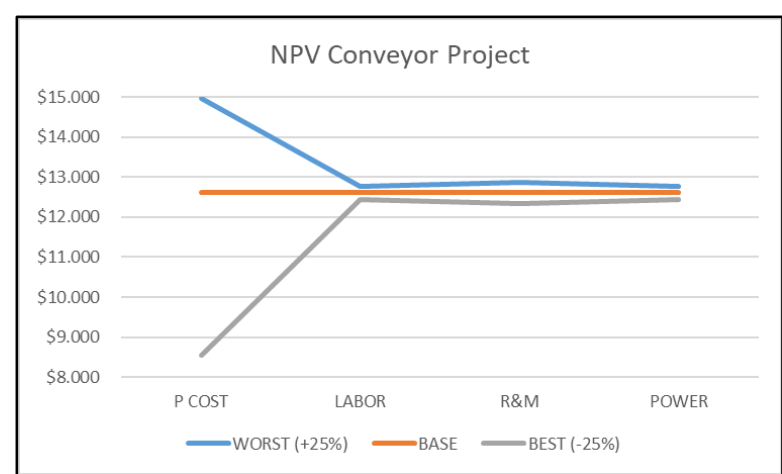

Gambar 2 Analisis Sensitivitas terhadap Hasil NPV Sistem Belt Conveyor 


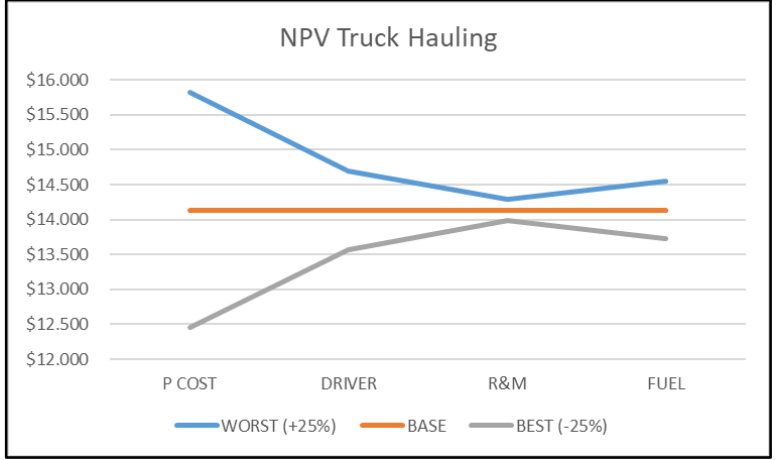

Gambar 3 Analisis Sensitivitas terhadap Hasil NPV Sistem Dump Truck

Tiga skenario telah ditentukan dengan asumsi skenario terburuk terjadi peningkatan biaya sebesar $(+25 \%)$. Kemudian skenario basis tidak terjadi perubahan biaya. Pada skenario terbaik terjadi penghematan biaya sebesar $(-25 \%)$ dari yang telah diestimasikan. Berdasarkan hasil analisis sensitivitas di atas, dapat disimpulkan beberapa hal sebagai NPV paling sensitif terhadap perubahan biaya proyek pada kedua alternatif, yang dapat digambarkan dari gradien terbesar atau garis paling curam. Berdasarkan angka-angka di atas, penulis mendapat perubahan di semua hal masih membuat kedua alternatif layak untuk dipilih.

\section{KESIMPULAN}

Tujuan dari penelitian ini adalah untuk penilaian komparatif kelayakan finansial antara proyek pembangunan belt conveyor dengan investasi angkutan truk berdasarkan kriteria capital budgeting ditinjau dari Net Present Value (NPV), Internal Rate of Return (IRR), dan Discounted Payback Period (DPP). Berdasarkan hasil analisis sensitivitas dalam rentang perubahan masing-masing variabel terkait pada skenario sensitivitas, hasil untuk semua kriteria persyaratan penganggaran modal masih dapat diterima. Jadi kedua alternatif investasi tersebut masih layak bahkan dalam skenario terburuk. Meski demikian, alternatif investasi belt conveyor lebih ekonomis daripada dump truck. Hal ini disebabkan oleh hasil Net Present Value yang lebih rendah. Kemudian disarankan untuk menggunakan metode kualitatif dan mengeksplorasi negara atau industri lain dalam penelitian selanjutnya, sehingga data yang diperoleh dapat lebih komprehensif dalam hal mendapatkan gambaran yang lebih luas tentang manfaat menggunakan model penganggaran modal dengan analisis sensitivitas untuk studi kelayakan.

\section{REFERENSI}

Almeida, C. M. De, Neves, T. D. C., Arroyo, C., \& Campos, P. (2019). Proceedings of the 27th International Symposium on Mine Planning and Equipment Selection - MPES 2018. In Proceedings of the 27th International Symposium on Mine Planning and Equipment Selection - MPES 2018. Springer International Publishing.

Carrêlo, I. B., Almeida, R. H., Narvarte, L., Martinez-Moreno, F., \& Carrasco, L. M. (2020). Comparative analysis of the economic feasibility of five large-power photovoltaic irrigation systems in the Mediterranean region. Renewable Energy, 145, 2671-2682.

CEMA. (2002). Belt Conveyors for Bulk Materials (The Scribe and Word Warriors (ed.); Fifth Edit). Conveyor Equipment Manufacturers Association.

Chan, F. T. S., Ip, R. W. L., \& Lau, H. (2001). Integration of expert system with analytic hierarchy process for the design of material handling equipment selection system. Journal of Materials Processing Technology, 116(2-3), 137-145.

Dai, J. B., \& Lee, N. K. S. (2012). Economic feasibility analysis of flexible material handling systems: A case study in the apparel industry. International Journal of Production Economics, 136(1), 28-36.

Engholm, A., Pernestål, A., \& Kristoffersson, I. (2020). Cost analysis of driverless truck operations. Transportation Research Record, 2674(9), 511-524.

Hang, D., McFadden, D., Train, K., \& Wise, K. (2016). Is vehicle depreciation a component of marginal travel cost?: A literature review and empirical analysis. Journal of Transport Economics and Policy, 50(2), 132-150.

Hassan, M. M. D. (2010). A framework for selection of material handling equipment in manufacturing and logistics facilities. Journal of Manufacturing Technology Management, 21(2), 246-268.

Hedianto, D., \& Daryanto, W. M. (2019). The analysis of capital budgeting model for the overland conveyor and ship loading facilities project of pt abc. International Journal of Business, Economics and Law, 19(1), 30-39.

Ioannou, G. (1999). Use of activity-based costing and economic value analysis for the justification of capital investments in 
automated material handling systems. International Journal of Production Research, 37(9), 2109-2134.

Lester, A. (2017). Project Management, Planning and Control (Seventh Ed). Elsevier Ltd.

Marufuzzaman, M., Ekşioğlu, S. D., \& Hernandez, R. (2015). Truck versus pipeline transportation cost analysis of wastewater sludge. Transportation Research Part A: Policy and Practice, 74, 14-30.

Masaki, M. S., Zhang, L., \& Xia, X. (2017). A Comparative Study on the Cost-effective Belt Conveyors for Bulk Material Handling. Energy Procedia, 142, 2754-2760.

Matson, J. O., Mellichamph, J. M., \& Swaminathan, S. R. (1992). EXCITE: Expert consultant for in-plant transportation equipment. International Journal of Production Research, 30(8), 1969-1983.

Ribeiro, B. G. C., de Sousa, W. T., \& da Luz, J. A. M. (2016). Feasibility project for implementation of conveyor belts in an iron ore mine. Study case: Fabrica Mine in Minas Gerais State, Brazil. Revista Escola de Minas, 69(1), 79-83.

Rudianto, S., \& Hartanto, T. (2020). Strategi Transportasi Batubara - Membandingkan Overland Conveying Dengan Truk Pengangkut Batubara. In Prosiding Temu Profesi Tahunan PERHAPI (Vol. 1, Issue 1, pp. 147-158).

Sakka, E. G., Bilionis, D. V., Vamvatsikos, D., \& Gantes, C. J. (2020). Onshore wind farm siting prioritization based on investment profitability for Greece. Renewable Energy, 146, 2827-2839.

Sdoukopoulos, E., Boile, M., \& Anagnostopoulou, A. (2015). Estimating truck operating costs for domestic trips case studies from Greece. Logistics \& Sustainable Transport, 6(1), 41-49.

Sevim, H., \& Sharma, G. (1991). Comparative economic analysis of transportation systems in surface coal mines. International Journal of Surface Mining , Reclamation and Environment, January 2012, 37-41.

Shakantu, W., Muya, M., Tookey, J., \& Bown, P. (2012). Evaluating Truck Empty Running in Construction: A Case Study from Cape Town, South Africa. Construction Economics and Building, 8(2), 41-49.

Siddhartha Ray. (2008). Introduction to Materials Handling. NEW AGE INTERNATIONAL (P) LIMITED,
PUBLISHERS.

Stopford, M. (2009). Maritime Economics (Third edit). Routledge.

Sullivan, W. G. (2015). Engineering Economy (Sixteenth). Pearson Higher Education, Inc.

Tompkins, J. A. (1984). Facilities Planning. Wiley.

Wheeler, C. A. (2019). Development of the rail conveyor technology. International Journal of Mining, Reclamation and Environment, 33(2), 118-132. 